\title{
An Interesting Presentation of Pheochromocytoma
}

\author{
Sunil Kumar Garg, Pragya Garg, Mehmet Urumdas \\ Department of Critical Care Medicine, NMC Hospital, Dubai, United Arab Emirates
}

\section{Abstract}

Pheochromocytoma is a rare cause of hypertension, but it could have severe consequences if not recognized and treated appropriately. Pheochromocytoma classically presents with paroxysms of hypertension and adrenergic symptoms including classic triad of episodic headache, sweating, and tachycardia. The clinical presentation of pheochromocytoma can mimic a number of other medical conditions including migraine, cardiac arrhythmias, myocardial infarction, and stroke, thus making the diagnosis of pheochromocytoma difficult, and treatment is directed toward presenting issue rather than underlying problem in such patients. We present a case of a 41 -year-old male patient who presented with cerebellar infarct and found to have aortic thrombi and later developed acute myocardial infaction during same hospitalization. To the best of our knowledge, this is the first reported case of this kind.

Keywords: Acute cerebellar infarct, acute myocardial infarction, aortic thrombi, pheochromocytoma

\section{INTRODUCTION}

Pheochromocytoma is rare catecholamine-secreting neuroendocrine tumors arising from chromaffin tissue in the adrenal medulla or extraadrenal paraganglia. It occurs with an annual incidence of approximately 2-8 million person-years and rare cause of hypertension in the general population, representing $<0.2 \%$ of cases. ${ }^{[1,2]}$

Pheochromocytoma has classic triad of symptoms, but most do not present with this. It has atypical presentations in $9 \%-10 \%$ which often delay diagnosis. ${ }^{[1]}$ Even with classical presentations, the diagnosis is often missed for a number of years unless the patient is evaluated in a center experienced in this disease. ${ }^{[3]}$

\section{Case Report}

A 41-year-male presented with $6 \mathrm{~h}$ history of sudden onset dizziness, vomiting, and difficulty in walking. His BMI was 28.3. On evaluation, he was conscious, oriented with heart rate $81 / \mathrm{min}$ regular, blood pressure $220 / 120 \mathrm{mmHg}$, and normal temperature. Examination was relevant for the presence of gaze-evoked nystagmus, impaired finger-nose test, trucal, and gait ataxia. MRI brain showed acute left cerebellar infarct. He was shifted to Intensive Care Unit on labetalol infusion. His past medical history was not significant except the diagnosis

\begin{tabular}{|l|l|}
\hline \multicolumn{3}{|c|}{ Access this article online } \\
\hline Quick Response Code: & Website: \\
& www.ijccm.org \\
\cline { 2 - 2 } & \\
\end{tabular}

of hypertension 1 year back for which he was not taking any treatment. His admission laboratory values were significant for leukocytosis and high fasting sugar but normal glycosylated hemoglobin and lipid profile.

On the next day, he complained of severe chest pain with radiation to upper back, so clinical suspicion of dissection was made and computed tomography (CT) aortogram done which revealed no evidence of dissection, but four small floating thrombi in the ascending aorta near junction with arch measuring 10-11 mm along with well-defined round-to-ovoid soft-tissue density lesion measuring $4.1 / 3.1 \mathrm{~cm}$ in the left suprarenal region [Figures 1 and 2]. He was initiated on enoxaparin and warfarin in addition to oral labetalol, perindopril, aspirin, atorvastatin, and nitroglycerin. At this time, there was no evidence of active coronary ischemia based on echocardiography, electrocardiogram, and troponin results and CT neck and cerebral angiography were unremarkable.

He was investigated for hormonal excess in view of adrenal mass and hypertension. On $5^{\text {th }}$ day while awaiting hormonal report, he developed chest pain and neck pain again. This time electrocardiogram revealed fresh changes in precordial

Address for correspondence: Dr. Sunil Kumar Garg, NMC Hospital, Dubai, United Arab Emirates. E-mail: sucare12@yahoo.co.in

This is an open access article distributed under the terms of the Creative Commons Attribution-NonCommercial-ShareAlike 3.0 License, which allows others to remix, tweak, and build upon the work non-commercially, as long as the author is credited and the new creations are licensed under the identical terms.

For reprints contact: reprints@medknow.com

How to cite this article: Garg SK, Garg P, Urumdas M. An interesting presentation of pheochromocytoma. Indian J Crit Care Med 2018;22:40-2. 


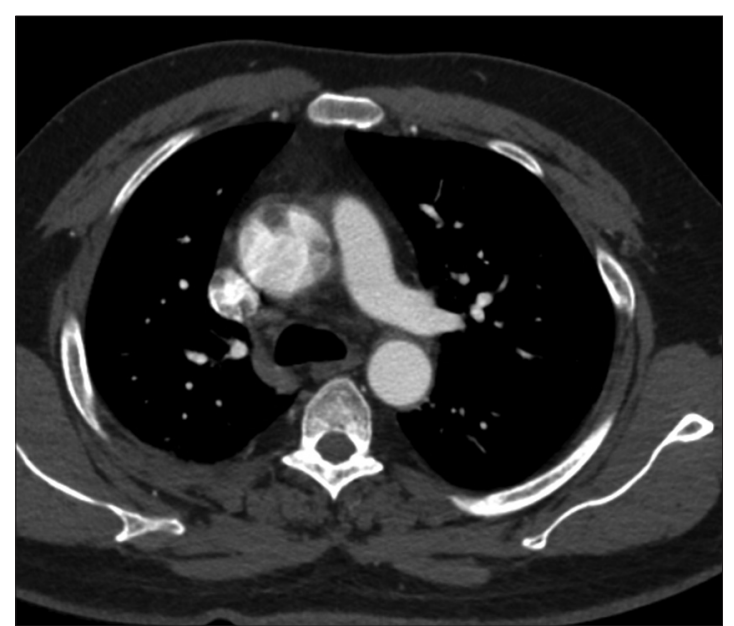

Figure 1: Filling defect due to thrombi in ascending aorta

leads (biphasic T-waves in V2-V4), positive and rising troponin, and new onset of regional wall motion abnormality in anterior wall and septum confirming non-ST elevation myocardial infarction. He was started on bisoprolol, and labetalol was stopped. The patient refused for coronary angiography and requested to go back to his home country for further management. The patient left for his home country on the same day and lost to follow-up. On $6^{\text {th }}$ day, laboratory investigation reports confirmed pheochromocytoma as his plasma metanephrines, and urinary catecholamines were significantly elevated. His plasma-free metanephrine level was $76 \mathrm{pg} / \mathrm{ml}$ and urinary dopamine and norepinephrine $512 \mathrm{ug} / \mathrm{g}$ creat and $126 \mathrm{ug} / \mathrm{g}$ creat, respectively.

\section{Discussion}

Pheochromocytoma is known to have varied clinical presentation. However, the presence of stroke, aortic thrombi, and myocardial infarction in one patient during single hospitalization has not been reported in medical literature. We also suspected thrombophilia initially; however, there was no evidence of venous thrombosis and presence of adrenal mass in hypertensive patient lead us to look for pheochromocytoma.

The clinical presentation of pheochromocytoma is mainly attributable to the excessive secretion of catecholamines. ${ }^{[4]}$ Approximately $91 \%$ of pheochromocytoma patients present with typical symptoms. The remaining $9 \%-10 \%$ present with atypical symptoms such as weakness, chest pain, paralysis, or claudication.

Atypical central nervous system symptoms are mainly due to ischemia. ${ }^{[1]}$ Cerebral ischemia leading to neurological features is a rare manifestation of pheochromocytoma. Various factors considered responsible for cerebral ischemia include severe hypertension with deranged cerebrovascular autoregulation, cerebral vasospasm, thrombosis in situ, or embolization from a left ventricular thrombus. ${ }^{[1]}$ Since a CT cerebral angiographic study was normal in our case, we cannot precisely pinpoint the cause as there was presence of aortic thrombi also. The precise

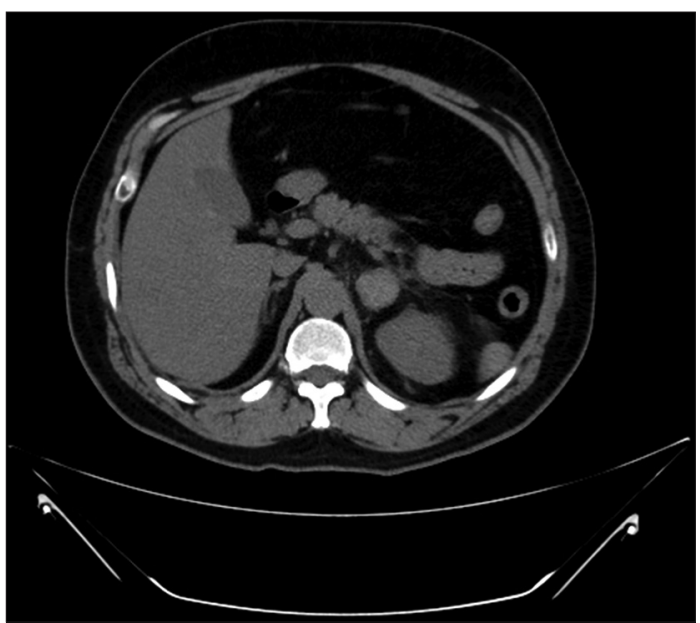

Figure 2: Left adrenal mass

vascular cause of such a stroke can seldom be determined with certainty. Our patient showed disappearance of neurological signs within $24 \mathrm{~h}$.

Pheochromocytoma can result in various cardiac manifestations including ventricular hypertrophy, myocarditis, dilated cardiomyopathy, and congestive heart failure or occasionally, as in our case, acute coronary ischemia. ${ }^{[5]}$ During a pheochromocytoma crisis, a myocardial oxygen demand-supply mismatch can occur due to an increased afterload (vasoconstriction), catecholamine driven tachycardia, and catecholamine-driven coronary vasospasms. ${ }^{[5]}$ This can precipitate myocardial ischemia with concomitant electrocardiographic and cardiac enzyme abnormalities, even in the absence of coronary atherosclerosis. ${ }^{[5]}$ In general, patients presenting with symptoms and signs of an acute myocardial infarction will be treated with $\beta$-adrenergic blockage. However, in the presence of a pheochromocytoma, inhibition of $\beta$-adrenergic receptors will cause paradoxically increased blood pressure due to unopposed $\alpha$-adrenergic receptor stimulation, thus further aggravating the condition of the patient as it happened in our patient. When our patient developed acute coronary ischemia, we changed his labetalol to bisoprolol which led to marked rise in his blood pressure again. This rise in blood pressure was due to initiation of bisoprolol, or merely a manifestation of episodic nature of pheochromocytoma cannot be ascertained definitely. Our patient had recurrent chest pain and which occurred even when the patient was on full medical management including aspirin, atorvastatin, and enoxaparin and it always improved spontaneously.

Numerous published reports have documented the association of pheochromocytoma with the development of systemic and intracardiac thrombi. ${ }^{[6]}$ It is likely that catecholamines and other hormones secreted by pheochromocytoma may play an important role in the pathogenesis of thrombosis. ${ }^{[3]}$ It has been reported that platelet aggregation is increased in patients with a pheochromocytoma. ${ }^{[7,8]}$ Of the 28 patients reported in the literature, a left ventricle thrombus was identified in eight. Inferior vena cava thrombi were present in 13 patients. ${ }^{[6]}$ 
Only one case report has documented an association between pheochromocytoma and an isolated acute arterial thrombosis. ${ }^{[9]}$

\section{ConcLusion}

The diagnosis of pheochromocytoma is challenging because the symptoms can be episodic and the overall incidence and index of suspicion are low. Whenever, a patient who presents with unusual clinical manifestations or course of organ ischemia along with hypertension which is difficult to control with conventional oral or intravenous antihypertensives, it should be suspected. Failure to diagnose and treat the underlying disorder has its own consequences including wrong management and mortality. Management of its all manifestations is primarily based on the control of excessive catecholamine release.

\section{Declaration of patient consent}

The authors certify that they have obtained all appropriate patient consent forms. In the form the patient(s) has/have given his/her/their consent for his/her/their images and other clinical information to be reported in the journal. The patients understand that their names and initials will not be published and due efforts will be made to conceal their identity, but anonymity cannot be guaranteed.

\section{Financial support and sponsorship}

Nil.

\section{Conflicts of interest}

There are no conflicts of interest.

\section{References}

1. Rupala K, Mittal V, Gupta R, Yadav R. Atypical presentation of pheochromocytoma: Central nervous system pseudovasculitis. Indian J Urol 2017;33:82-4.

2. Pacak K, Linehan WM, Eisenhofer G, Walther MM, Goldstein DS. Recent advances in genetics, diagnosis, localization, and treatment of pheochromocytoma. Ann Intern Med 2001;134:315-29.

3. Hou R, Leathersich AM, Ruud BT. Pheochromocytoma presenting with arterial and intracardiac thrombus in a 47-year-old woman: A case report. J Med Case Rep 2011;5:310.

4. Bravo EL. Evolving concepts in the pathophysiology, diagnosis, and treatment of pheochromocytoma. Endocr Rev 1994;15:356-68.

5. Menke-van der Houven van Oordt CW, Twickler TB, van Asperdt FG, Ackermans P, Timmers HJ, Hermus AR, et al. Pheochromocytoma mimicking an acute myocardial infarction. Neth Heart $J$ 2007; 15:248-51.

6. Kaiser S, Chronakos J, Dietzek AM. Acute upper extremity arterial thrombosis and stroke in an unresected pheochromocytoma. J Vasc Surg 2013;58:1069-72.

7. Danta G. Pre- and postoperative platelet adhesiveness in pheochromocytoma. Thromb Diath Haemorrh 1970;23:189-90.

8. Nakada K, Enami T, Kawada T, Hoson M, Wakisaka M, Mochizuki A, et al. Characterization of platelet activity in neuroblastoma. J Pediatr Surg 1994;29:625-9.

9. Raghavan R, Ince PG, Walls TJ, Gholkar A, Dark JH, Foster JB, et al. Malignant cerebrovascular thromboembolization by phaechromocytoma Clin Neuropathol 1995;14:69-71. 